\title{
TATIANA ZiNOWJEWA
}

\section{Еще раз о финальных кластерах с сонантами}

К лючевы е с лова: финальные кластеры с сонантами; гласная вставка; фонематический статус

Key words : final clusters with sonants; vocalic infix; phonemic status

Вопрос о так называемых слоговых сонантах в русском языке', а точнее о гласной вставке, появляющейся в финальных консонантных кластерах с сонорными, а также происхождение и фонематический статус такой эпентезы затрагивался не раз. Исследователи (Р.Ф. Касаткина, вслед за М.В. Пановым) пришли к выводу, что флуктуации вокальности, возможные не только в финальных сочетаниях 'шумный + сонорный', 'шумный + [в]', но и 'шумный + шумный', можно рассматривать как «реализацию потенциально возможного беглого гласного», что свидетельствует о наличии «скрытой памяти языка о редуцированном» в этой позиции. В свою очередь, возникающие в перечисленных сочетаниях незакономерные элементы, этимология которых не связана напрямую с редуцированными гласными, также исследовались учеными. Наличие таких неэтимологических гласных в древнерусский

1 Настоящими слоговыми сонантами считаются «сонанты, образующие слог без участия вставного гласного типа немецкого bieten [bi:-tn] или английского Clinton [klin-tn]» (Князев, Пожарицкая 2011, с. 137). 
период единодушно признавалось историками русского языка (в частности, В.М. Марковым, А.В. Исаченко, В.В. Колесовым, М.Б. Потаповым, Л.П. Жуковской). Тем не менее, «до сих пор в науке не существует единого мнения по поводу преемственности между древнейшими неорганическими гласными и многочисленными нефонематизированными неорганическими гласными вставками современного русского языка» (Баранов 1997, с. 138).

Сама возможность произношения кластеров типа $-C R$ с гласной вставкой многократно наблюдалась и описывалась исследователями как в говорах, так и в литературном русском языке, начиная с конца XIX века (подробнее об этом см.: Панов 1990). Проводились и экспериментальные исследования неорганической гласности. Там не менее, еще в 90-е годы XX века один из исследователей этого явления справедливо констатировал: «Несмотря на тщательное изучение гласных вставок с помощью экспериментальных методов (Л.В. Златоустова, Р.Ф. Пауфошима, И.С. Никольская, О.П. Агапкина), получение большого количества фактического материала при работе над Диалектологическим атласом русского языка и предварительную его обработку с помощью метода лингвистической географии (Е.Г. Бурова), несмотря на обращение к примерам с гласными вставками в связи с проблемой вариантности диалектного слова (О.И. Блинова, О.Д. Кузнецова) в настоящее время широко распространен взгляд на неорганическую гласность как на явление, находящееся на периферии фонетической системы русского языка, а сами неорганические гласные понимаются как нечто застывшее в структуре формы, не имеющее ни динамических свойств, ни фонологической нагрузки» (Баранов 1991, с. 1).

Однако позднее ученые обращались к вопросу возможной фонематизации таких гласных вставок в современном русском языке: «Мерцающая, пульсирующая вокальность, своего рода «фантом F», по выражению Михаила Викторовича Панова (Панов 2004) - вот как можно назвать обсуждаемый феномен», - пишет Р.Ф. Касаткина (Касаткина 2010). Термин «фантом F» был заимствован М.В. Пановым у Станислава Лема и в контексте фонематического статуса упомянутой вокальности означает наличие инструментально подтвержденной гласной вставки при одновременном отсутствии у нее существенных признаков фонемы. Как пишет М.В. Панов: «стал ли гласный [ъ] в слове смотр, 
вётл фонемно существенным, не определить по показаниям аппарата [...]. Надо исследовать его поведение. В нашем случае: [ъ] - фантом может доходить до нуля, а [ъ] - нефантом не может (в нейтральном стиле произношения в указанной позиции). Поэтому слово педиатр может восприниматься и как педиатор: фантом колеблется меж нулем и [ъ]; но ритор не воспринимается как ритр. Значит, фантом пока еще в этом случае остается фантомом: его поведение не то, что у гласного, представляющего фонему» (Панов 2004, с. 409-410).

Это мнение долгое время казалось неоспоримым. Однако в течение последнего десятилетия появились новые обстоятельства и возможности, позволяющие перепроверить данное утверждение.

Прежде всего, обращает на себя внимание значительное количество ошибочных написаний, которыми пестрит сегодня сеть Интернет. В контексте приведенного выше утверждения М.В. Панова особый интерес вызывают ошибочные написания слов с искусственно образующимися кластерами в результате игнорирования предшествующей сонанту буквы, передающей полноценную слогообразующую гласную, авторами которых являются взрослые интернет-пользователи.

При более внимательном рассмотрении вся совокупность таких ошибочных написаний разбивается на две разновидности, а именно: на мотивированные и немотивированные ошибочные написания. Под мотивированным ошибочным написанием я понимаю преднамеренное искажение графического облика слова носителем языка, владеющим языковой нормой, за которым стоит определенная, преследуемая данным носителем цель.

Итак, к мотивированным ошибочным написаниям относятся, вопервых, эрративы ${ }^{2}$, широко используемые в интернет-сленге (или как его еще называют «языке падонков» или «олбанском языке»). Эта языковая девиация возникла во второй половине 90-х годов как языковая игра, предположительно в среде «новой интеллигенции» (по выражению А.И. Карасевой), получив широкое распространение среди менее образованных людей в 2006-2008 годах. Социально-демографический

2 Это понятие было введено Г.Ч. Гусейновым, который определяет его как «слово или выражение, подвергнутое нарочитому искажению носителем языка, владеющим языковой нормой» (Гусейнов). 
«портрет носителя сленга», созданный в ходе проведенного в 2007 году социологического исследования (Карасева 2008) ${ }^{3}$, не позволяет отнести его к носителям русского литературного языка, да и сленг уже по самому́ своему определению находится в оппозиции к литературному языку. Тем не менее, уже сам факт появления написаний без графемы, передающей слогообразующую гласную, предоставляет нам первые письменные свидетельства двух фонетических процессов, один из которых закончился, дав начало второму. Какие именно это свидетельства и процессы?

Так сегодня, то есть уже десять лет спустя достижения феноменом эрратографии 4 своего пикового уровня, мне удалось найти варианты эрративного написания отдельных, наиболее частотных для интернетсленга слов 5 без графемы, передающей гласный звук последнего слога: свыше 5 тысяч web-страниц, содержащих написание «аффтр» как вариант более частотного эрратива «аффтар» (автор), более 100 webстраниц, содержащих написание «кампазитр» как вариант более частотного эрратива «кампазитар» (композитор), а также менее частотные эрративы «ридактр» (редактор), «апиратр» (оператор), «риактр» (реактор), «каминтатр» (комментатор), и другие. Указать точное количество web-страниц, найденных для того или иного эрратива, не представляется возможным, поскольку даже при использовании расширенного поиска в поисковой системе Google с указанием точного написания словоформы, языка и региона поиска, поисковой системой учитываются в подсчетах слова с нормативным написанием, а также с непреднамеренно ошибочным написанием (опечатками) и нерусские слова.

3 Это активный пользователь Интернета (проводящий в сети более трех часов в день) со средним полным или средним специальным образованием, как правило, студент первого-второго курса, проживающий в одном из городов-миллионеров (Москве, Санкт-Петербурге, Новосибирске, Екатеринбурге), крупном городе (с населением более 500 тысяч) или прилегающей к нему области.

4 В дальнейшем использование эрративов получило название антиорфография, которое, в свою очередь, сменилось термином эрратография, понимаемым как «система ошибочных написаний», а эрратив стал считаться единицей эрратографии (Марченко 2012).

5 Для просчета количества web-страниц использовался расширенный поиск в поисковой системе Google с указанием точной словоформы. 
Bo-вторых, в группу так называемых мотивированных ошибочных написаний входят фирменные наименования компаний, подражающие звуковому облику наименований хорошо узнаваемых конкурентов. К примеру, имеются официально зарегистрированные фирменные наименования компаний с написанием без последней гласной буквы: ООО «Инвестр-ДВ», ООО «Инспектр», ООО «Агро-Сектр», ООО «Вектр-Л», ООО «Статр», ООО «Ритр». Такое написание, разумеется, призвано оградить поименованные компании от ответственности за неправомерное использование защищенных законом фирменных наименований, содержащих слова инвестор, инспектор, сектор, вектор, статор, ритор в их нормативном написании. Тем не менее, сама идея обращения к заведомо ошибочному написанию рассчитана на введение потенциального клиента в заблуждение именно при помощи остающегося неизменным фонетического облика слова, использованного в фирменном наименовании.

Иного рода примеры нам предоставляет получившее в последние годы широкое развитие явление креолизации текстов в русском языке. Сюда можно отнести создание графических окказионализмов как один из способов креолизации текстов, в которых обыгрывается слово «спектр», например, при помощи шрифтовыделения - инСПЕКТР (видеоблог, официальный канал на веб-сайте Youtube компании «Спектр Групп») ${ }^{6}$, ИнСпектр (фирменное наименование компании) $)^{7}$. В качестве еще одного примера креолизованного текста можно привести интернет-мем ${ }^{8}$, в котором использовано искусственное противопоставление спектр - инспектр с предположительно намеренным ошибочным написанием второго слова (рисунок 1$)^{9}$.

${ }^{6}$ Режим доступа: http://wehaveideas.ru/portfolio-item/inspektr-krasoty-youtube-kanal-dlya-seti/ (дата обращения: 17.09.2017).

7 Режим доступа: http://enspectr.ru/ru (дата обращения: 17.09.2017).

8 Креолизованным текстом особого рода считает интернет-мем С.В. Канашина (Канашина 2016).

9 Режим доступа: http://muhom.org/2015/11/09/spektr-vs-inspektr/ (дата обращения: 01.01.2018). 


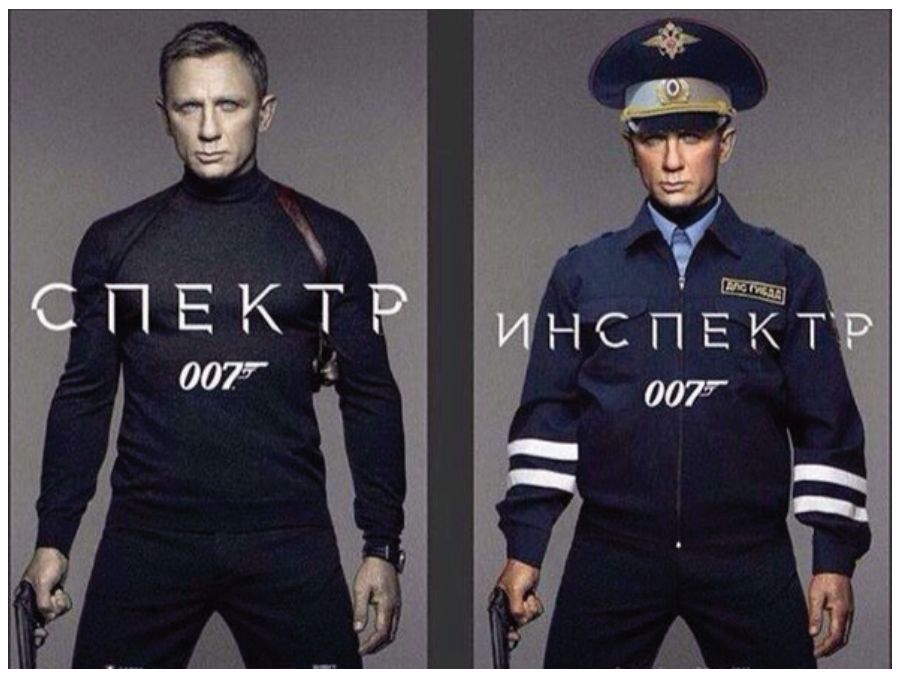

Рисунок 1

С другой стороны, мы имеем группу немотивированных ошибочных написаний. Это, в первую очередь, заимствования из английского языка. Среди них обращает на себя внимание существительное риелтор, сравнительно недавно активно вошедшее в русский обиход и на протяжении без малого 20 лет испытывавшее колебания в написании ${ }^{10}$. Сегодня в сети Интернет среди других ошибочных написаний данного слова (таких, как риэлтор, риелтер и т.п.), встречается также написание без последней гласной, то есть риелтр и риэлтр (в общей сложности на более 10000 web-страниц агентств недвижимости и агентств по трудоустройству, а также частных лиц, рекламирующих свои услуги). Другим примером такого рода может послужить заимствование из английского экшен и производные от него сложные слова (экшен-фильм, экщен-сцена, экшен-герой, экшен-литература, экшен-камера). Поиски в сети Интернет, а также в Национальном корпусе русского языка демонстрируют гораздо более высокую частотность варианта экшн по сравнению с написанием экшен, рекомендуемым орфографическими словарями.

10 Начиная с 1998 года различными словарями и справочниками было зафиксировано не менее четырех возможных варинтов написания этого слова: риелтор, риелтер, риэлтор, риэлтер. 
В качестве любопытного примера еще одного, предположительно немотивированного ошибочного написания, можно привести рекламную акцию с ошибочным написанием существительного инвестор (рисунки 2 и 3). В данном случае, вероятно, графический облик слова без предшествующей сонанту буквы «о», так сказать, «навеян» аналогией с достаточно многочисленной группой существительных с кластером [стр] в финали: оркестр, министр, магистр, реестр, монстр, бургомистр и пр. ${ }^{11}$ Данный пример примечателен, кроме того, использованием параграфемных элементов - иноязычных вкраплений в виде целостных лексических единиц (fitness, SPA) и символа российского рубля - буквы «р» с дополнительным элементом в виде горизонтальной черты в качестве последней буквы существительного инвестор).

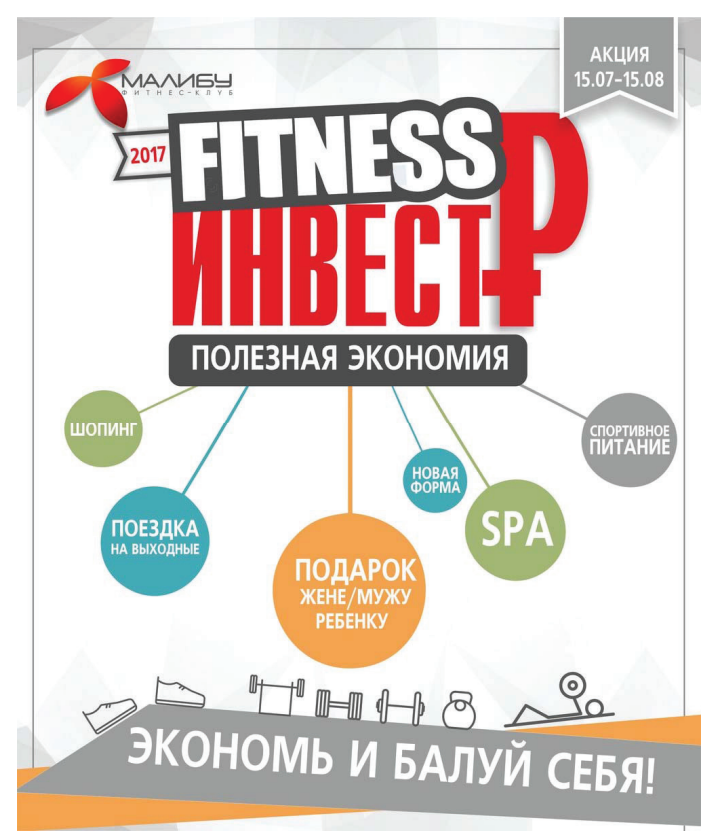

\section{Рисунок 2}

11 Режим доступа: http://www.malibu42.ru/poslednie-novosti/fitness-investr-188. html (дата обращения: 17.09.2017). 


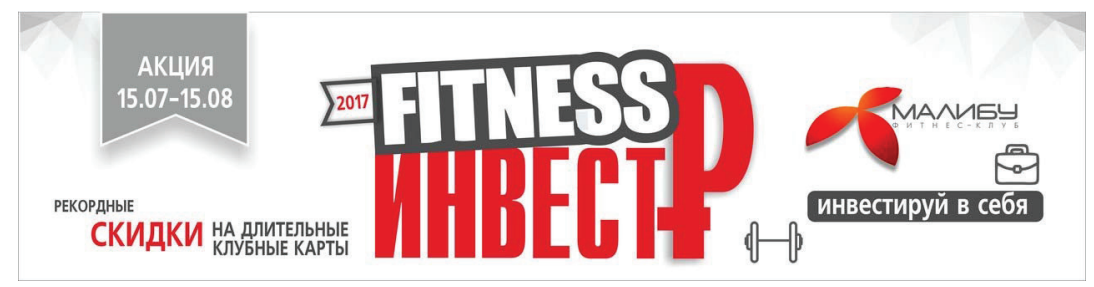

\section{Рисунок 3}

Ошибочные написания свидетельствуют, прежде всего, о том, что кластер с сонантом в финали в современном русском языке уже не произносится без гласной вставки (с так называемым квазислоговым сонантом), и наоборот: наличие оппозиции «ноль гласного» - [ъ] в живой речи при произношении данных групп должно было бы по-прежнему поддерживаться на графическом уровне. Не происходит и оглушения сонантов после глухого согласного (что также подтверждается многочисленными наблюдениями), хотя еще не так давно оглушение последнего сонорного было свойственно литературному русскому языку (Касаткин 1999, с. 275).

Кроме того, столь богатый так называемый «антиорфографический» материал, на мой взгляд, является свидетельством наличия в современном русском языке нового активного фонетического процесса выравнивания двух схожих последовательностей звуков, в ходе которого слогообразующая безударная гласная [ъ] последнего слога если и не доходит до нуля (как это постулировал М.В. Панов), то уже приравнивается в восприятии носителей русского языка к гласной вставке, реализуемой в кластерах с сонантами (см. осцилограммы 1 и 2). Визуальная оценка таких примеров достаточно проблематична, поскольку любое произношение плавного сонанта, в том числе в соседстве с гласным, всегда сопровождается вокальными элементами - как до, так и после консонантного элемента, а иногда и с обеих его сторон. Кроме того, сравнительно бо́льшая или меньшая продолжительность реализации сонанта не всегда соответствует ее перцептивной оценке как реализации с вокалической вставкой или без нее. Более достоверные результаты, на мой взгляд, мог бы дать эксперимент, основанный на проверке восприятия на слух включенных в словосочетания фонетических слов, составляющих ми- 
нимальные пары. Помимо уже указанных разичными фонетистами минимальных пар, таких как контур и контр- (Панов 2004, с. 409), кадр и Янош Кадар (Князев 1999, с. 84), сидр и Сидор, шторм и шторам, цуикл и цุикал, догм и догам/догом, холм и холлам/холлом, рифм и рифам/pифом, ритм и Ритам (Шеворошкин 1969, с. 15), можно привести и другие квазиомонимы: кластер ('объединение нескольких однородных элементов’) и Кластр ('коммуна во Франции', ‘фамилия французского происхождения'); огар ('порода охотничьих собак, выведенная в Польше') и огр ('злобный великан-людоед из кельтской мифологии'); электор ('избиратель') и электр ('сплав золота и серебра'); Кастор ('имя мифологического персонажа', 'название звезды') и Кастр ('название города, округа и департамента во Франции'). Если результаты такого эксперимента покажут неразличение носителями русского языка данных минимальных пар в идентичном фонетическом окружении, можно будет сделать вывод о перцептивной идентичности групп со слогообразующей исконной безударной гласной и кластеров с гласной вставкой, а следовательно, и о той инструментально регистрируемой разнице между ними, которая, несомненно, останется и будет по-прежнему фиксироваться, но уже как опциональная, не зависящая от происхождения.

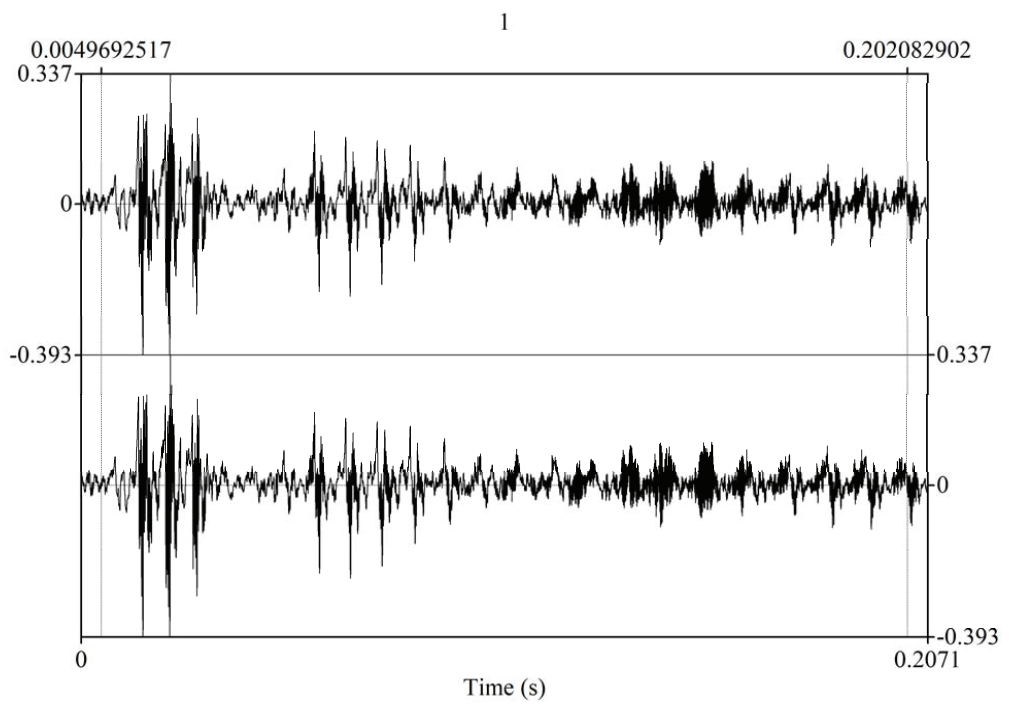

Осцилограмма 1. [тър\#з] из словосочетания автор зажигает 


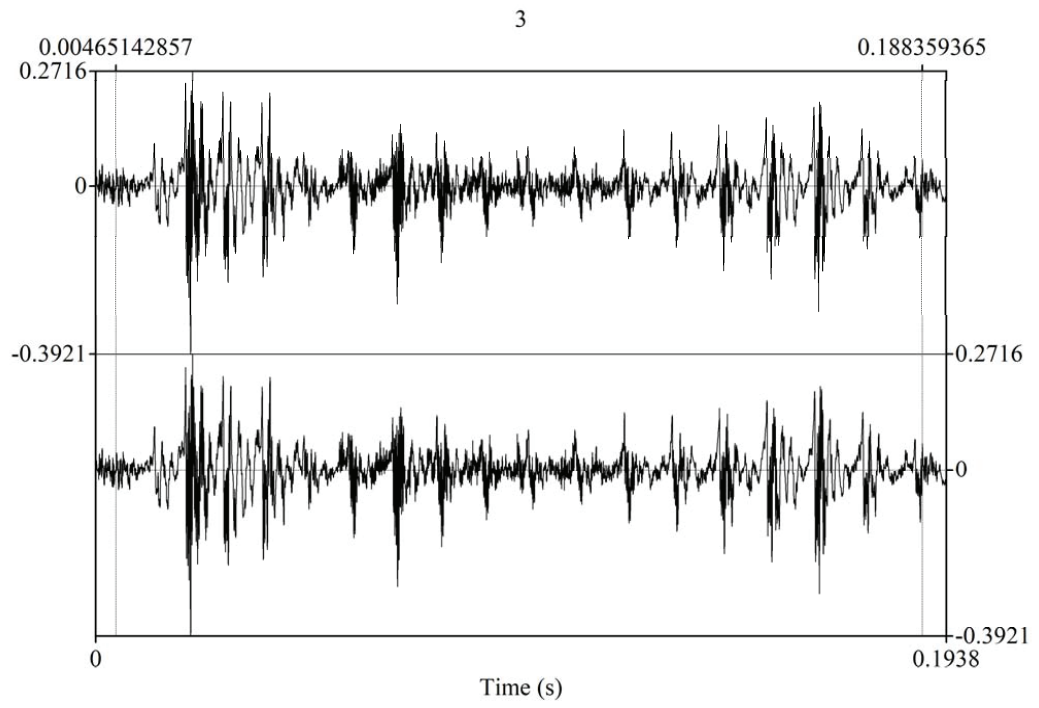

Осцилограмма 2. [тър\#3] из словосочетания Пётр зарабатьєвает

Открытым остается и вопрос отнесения рассматриваемого «фантома» к определенной фонеме в рамках какой-либо фонологической школы. Вряд ли стоит рассматривать возможность появления собственно слоговых сонорных фонем в русском языке, но можно ли соотносить их с гиперфонемой $<\mathrm{a} / \mathrm{o} / \mathrm{e}>$ либо архифонемами /O/ или /A/ - на этот вопрос еще предстоит ответить. Рассматриваемый фантом появляется в позиции полной нейтрализации всех невысоких гласных. Однако в современных теориях, уже не обращающихся к понятиям архифонемы или гиперфонемы, такой аллофон следовало бы отнести к конкретной фонологической единице. В данном случае сделать это невозможно ввиду отсутствия вокальной морфонемы. Сложно также предположить наличие нейтрализации между гласной и сонантом в данной позиции, поскольку речь может идти лишь о части реализации сонанта. Таким образом, остается лишь арбитрально выбрать гласную фонему, возможно на основании статистически более частотного появления в данном контексте?

Эволюция произношения ауслаутных кластеров с сонантами после глухих согласных произошла при жизни всего лишь одного поколения. Здесь я имею в виду последнее поколение, принадлежащее к «оранже- 
вой» системе согласно М.В. Панову ${ }^{12}$. Ни один из двух вариантов произношения таких кластеров, характерных для носителей литературного русского языка «оранжевой» системы и наблюдаемых А.А. Реформатским, Л.Л. Касаткиным, М.В. Пановым (в один слог - с квазислоговым сонантом или с оглушением), не реализуется младшими поколениями (Реформатский 1971, Касаткин 1999, Панов 1967). Среди более молодых носителей литературного русского языка (представителей «алой» системы) произношение с гласным элементом является уже полностью господствующим. Как пишет М.В. Панов: «Произносят: теá[тър] (как ле́к[тър]), сми́́ [съл], макроко́[съм] и т.д. Очень устойчиво такое произношение после звонких шумных согласных: бо[дър], же[зъл], греци́[зъм]. В оранжевой системе наряду с такой нормой после глухих согласных вместо сочетаний гласного с сонорным нередко возможен просто глу-

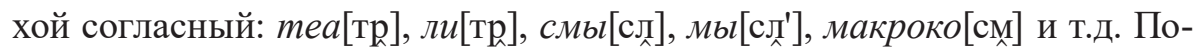
сле звонких согласных (в словах типа бодр, жезл) такое произношение редкостно и у „оранжевых” носителей языка. Если произносятся глухие сонорные [p], [л], [м], [н] (и их мягкие „собратья”), то, естественно, слога они не образуют» (Панов 1990, с. 28-29).

Сложно установить, в какой момент произношение с гласной вставкой «внедрилось» в русскую произносительную норму. В один и тот же период (конец 60-х - начало 70-х годов) одни авторы не считали артикуляцию с «полным» гласным нормой русского произношения (Шеворошкин 1969, с. 15), допуская в качестве разговорно-нейтральных лишь «слоговые сонанты», а варианты с гласным пазвуком относили к признакам нелитературного просторечия (Григорьев 1971, с. 48), другие допускали присутствие гласных перед сонорными и в разговорном, и в нейтральном стилях (Панов 1967, с. 269-270). Л.В. Златоустова, экспериментально исследуя произношение односложных слов с сонантами в финали, констатировала наличие гласной вставки, характеристики которой сопоставимы с характеристиками долготы безударных глас-

12 В периодизации русского литературного произношения М.В. Панов насчитывает пять эпох, в последней из которых (XX век) автор выделяет две сосуществующие друг с другом системы: «оранжевую» (речь старшего поколения, начиная с 20-30-х годов) и «алую» (речь младшего поколения), справедливо замечая, что «в наше время речь младшего поколения отлична от речи старшего» (Панов 1990 , c. 13). 
ных 2-го предударного или заударного неконечного слогов «в любом стиле речи (полном или разговорном), при изолированном наговаривании и в предложениях» (Златоустова 1961, с. 31). Так или иначе, сегодня в результате уникального наложения в рассматриваемом контексте «оранжевой» и «алой» систем нам доступны диаметрально отличающиеся друг от друга реализации, - начиная с неслоговой, зачастую глухой реализации сонанта, к звонкой, переходящей в слоговую, и заканчивая выделением полноценного вокального элемента.

\section{Библиография}

Баранов В.А., 1991, Развитие неорганической гласности в русском языке. Автореферат на соискание ученой степени кандидата филологических наук, Ленинград: ЛГУ.

БАРАнов В.А., 1997, Неорганическая гласность и ударение, Sborník prací Filozofické fakulty brněnské univerzity, Studia minora facultatis philosophicae Universitatis Brunensis A 45, c. 137-147.

ГриГорьев В.П., 1971, Финали «согласный + сонант» в поэтической речи, в: Ф.П. Филин (отв. ред.), Фонетика. Фонология. Грамматика, Москва: Наука, с. $43-49$.

ГусЕйнов ГЧ., Берлога веблога. Введение в эрратическую семантику, [режим доступа]: http://www.speakrus.ru/gg/microprosa_erratica-1.htm.

ЗЛАтоустова Л.В., 1961, Научная деятельность В.А. Богородицкого, в: А.С. Фидровская (науч. ред.), Сборник «Памяти В.А. Богородицкого», Казань: Учен. зап. Казан. ун-та. Т. 119, кн. 5, с. 23-40.

КАНАшина С.В., 2016, Текстовые категории модальности и темпоральности в интернет-меме как образец современного креолизованного текста, Becmник Рязанского государственного университета им. С.А. Есенина. Литературоведение. Языкознание, № 1 (50), с. 79-87.

Карасева А.И., 2008, Роль и функции эрратива в Интернет-сленге, Мониторинг общественного мнения: экономические и социальные перемены, №2, c. 129-141.

КАСАТкин Л.Л., 1999, Современная русская диалектная и литературная фонетика как источник для истории русского языка, Москва: Издательство «Наука»; Школа «ЯРК».

КАСАТкина Р.Ф., 2010, А был ли парадокс? Еще раз к вопросу о произношении резв, трезв, язв в русском языке, в: В.З. Демьянков, В.Я. Порхомовский, М.Е. Алексеев и др., В пространстве языка и культуры: звук, знак, смысл. Сборник статей в честь 70-летия В.А. Виноградова, Cер. „Studia 
philologica" Российская академия наук, Институт языкознания. Москва: Языки славянских культур, с. 762-774.

Князев С.В., 1999, О критериях слогоделения в современном русском языке: теория волны сонорности и теория оптимальности, Вопросы языкознания, № 1, c. 84-102.

КнязЕв С.В., ПоЖАРИЦКАЯ С.К., 2011, Современный русский литературный язык. Фонетика, орфоэпия, графика и орфография, Москва: Гаудеамус, Академический Проект.

МАрченко Л.В., МАРченКО Н.Г., 2012, К вопросу о содержании термина «эрратография», в: В.Ю. Меликян (отв. ред.), Современный русский язык: актуальные вопросы теории и методики преподавания, Ростов-на-Дону: Дониздат, с. 139-147.

ПАнов М.В., 1967, Русская фонетика, Москва: Просвещение.

ПАнов М.В., 1990, История русского литературного произношения XVIII- ХХ вв., Москва: Наука.

Панов М.В., 2004, Труды по общему языкознанию и русскому языку, Т. 1, Москва: Языки славянских культур.

Реформатский А.А., 1971, Слоговые согласные в русском языке, в: С.С. Высотский (отв. ред.) и др., Развитие фонетики современного русского языка: Фонологические подсистемы, Москва: Наука, с. 200-208.

Шеворошкин В.В., 1969, Звуковые цепи в языках мира, Москва: Наука.

\section{Once more about final consonant clusters with sonants}

\section{(summary)}

The article deals with the evolution of the pronunciation of final consonant clusters with sonants in Modern Russian. An attempt was made to revise the previous views on the phonemic status of the vowel insertion in such clusters, taking into account the appearance of a significant number of conscious and unconscious new errors in spelling which do not recognize the mentioned clusters. 
